\title{
Regional differences in mitigation strategies: an example for passenger transport
}

\author{
Sebastiaan Deetman • Andries F. Hof • \\ Bastien Girod · Detlef P. van Vuuren
}

Received: 26 February 2013/Accepted: 12 June 2014/Published online: 25 July 2014

(C) Springer-Verlag Berlin Heidelberg 2014

\begin{abstract}
This paper shows the importance of including region-specific circumstances in long-term climate change mitigation strategies, by example of a modeling exercise of the transport sector. Important emission reduction options in the transport sector include biofuels, electric vehicles and efficiency standards. The most effective combination of these options depends, among others, on the availability of biofuels, the effectiveness of efficiency standards, and the (expected) emission intensity of the power sector-all of which differ between regions. Differences in climate policies between regions influence these factors. For instance, fuel efficiency standards slowdown the long-term transition in regions where plugin hybrid electric cars compete with gasoline cars (such as the USA or Europe) by
\end{abstract}

S. Deetman · A. F. Hof $(\bowtie) \cdot$ D. P. van Vuuren

PBL Netherlands Environmental Assessment Agency,

P.O. Box 303, 3720 AH Bilthoven, The Netherlands

e-mail: Andries.hof@pbl.nl

S. Deetman

e-mail: deetman@cml.leidenuniv.nl

D. P. van Vuuren

e-mail: Detlef.vanVuuren@pbl.nl

S. Deetman

Institute of Environmental Sciences, Leiden University,

P.O. Box 9518, 2300 RA Leiden, The Netherlands

B. Girod

Department of Management, Technology, and Economics, Chair of Sustainability and Technology, Swiss Federal Institute of Technology Zurich, Weinbergstrasse 56/58,

8032 Zurich, Switzerland

e-mail: bgirod@ethz.ch

D. P. van Vuuren

Department of Geosciences, Utrecht University,

P.O. Box 80125, 3508 TC Utrecht, The Netherlands decreasing the costs for driving gasoline costs and therefore in fact increase long-term emissions. Another example is that promoting electric vehicles is less effective in regions which are expected to rely heavily on fossil fuels for power generation, such as South Africa, China and India. Based on these findings from the TIMER energy model, we introduce an indicative region-specific framework for assessing mitigation strategies for the transport sector up to 2050, for different ambition levels of climate policy.

Keywords Climate change - Mitigation - Transport . Biofuels · Scenarios

\section{Introduction}

In the last few years, the scientific community has started to explore emission scenarios that achieve emission reduction targets aiming at limiting global temperature change to $2{ }^{\circ} \mathrm{C}$ or less (Calvin et al. 2012; Clarke et al. 2009; Edenhofer et al. 2010; van Vuuren et al. 2007). Most of these studies assume that climate goals are reached by implementing least-cost emission mitigation options, typically by implementing a global carbon tax. The focus on such cost-optimal scenarios is partly for methodological reasons, but also because modelers intend to inform policy makers about the cheapest way to achieve the required emission reductions. Given the focus on this generic-price instrument, studies pay little attention to the effectiveness of specific mitigation measures or to what implementation issues may arise (Deetman et al. 2013). In this paper, we explore how results from integrated assessment models may be used to guide long-term policy making in different regions, by example of the transport sector. 
There are various options to mitigate $\mathrm{CO}_{2}$ emissions from passenger cars. First of all, policies could aim at changing behavior, for instance through reducing the mileage (by increasing the price per kilometer) or through reducing the demand for vehicles (by increasing the vehicle price; Chapman 2007). But even if we focus only on the supply side of automotive technologies, vehicle weight reduction (Kim et al. 2011), biofuel blending, fuel efficiency improvements, hydrogen cars (Van Mierlo et al. 2006) and electric cars (Barkenbus 2009), all have the potential to lower the $\mathrm{CO}_{2}$ emissions per kilometer driven. Three of these options are of particular interest because of recent developments: new fuel efficiency standards are implemented in the United States of America (EPA and NHTSA 2012), the European Union has set renewable energy targets for transport-of which the major part is expected from biofuels (European Parliament and European Council 2009), and various European governments promote electric vehicles by rebates on purchase prices (Kley et al. 2012).

As these mitigation options interact with each other, with options to reduce $\mathrm{CO}_{2}$ emissions in other sectors, and with other policy goals, it is difficult for governments to decide on the preferred route of transition toward a lowcarbon transport system. For example, promoting diesel cars may increase overall fuel efficiency and thereby reduce $\mathrm{CO}_{2}$ emissions, but it also results in increased air pollution through higher emission of particulate matter (Mazzi and Dowlatabadi 2007). Furthermore, biofuels have potential co-benefits in generating employment and improving energy security (Berndes and Hansson 2007), but at the same time, it could threaten energy security if biofuels have to be imported, and it could challenge food security in some regions (Molony and Smith 2010). Electric vehicles have potential co-benefits in balancing the intermittent supply of renewable energy sources (Richardson 2013), but bear the potential to increase embodied emissions if the electricity stems from fossil power plants (Hawkins et al. 2013) and could be constrained by resource availability (Kushnir and Sandén 2012).

Given the multiple trade-offs and interactions between the mitigation options in the transport sector, the choices that today's policy makers are faced with are surrounded by complexities. Model analysis can help to unravel some of these complexities. In this paper, we use the results of model analysis to provide an indicative region-specific framework for assessing mitigation strategies for passenger transport. This framework is based on the outcomes of global emission scenarios with detail on several world regions (section "Results"). The framework itself is discussed in section "Discussion: a regional approach to clean transport technologies". The following section describes the methodology and main assumptions.

\section{Method and assumptions}

This study looks at two existing scenarios developed for the OECD Environmental Outlook 2012 (OECD 2012): a baseline scenario and a $450 \mathrm{ppm}$ mitigation scenario (called $450 \mathrm{ppm}$ Core in the OECD Environmental Outlook). In the latter scenario, $\mathrm{CO}_{2}$-equivalent concentrations are stabilized at $450 \mathrm{ppm}$, in line with the policy target of limiting climate change to $2{ }^{\circ} \mathrm{C}$. Both scenarios were developed by the IMAGE model framework (Bouwman et al. 2006), which includes the TIMER energy system simulation model (van Vuuren 2006). TIMER describes the demand and supply of various energy carriers and their transformation for 26 world regions on a yearly basis. The choice for the deployment of different energy technologies is based on their relative costs, which are in turn based on dynamics like fuel depletion and trade. TIMER explicitly models inertia due to stock lifetimes, which makes it a particularly useful model to study the long-term development of the energy system. In the $450 \mathrm{ppm}$ mitigation scenario, it is assumed that emission reductions are achieved at least costs over sources and regions.

Projections for energy consumption in the baseline roughly follow the projections of the IEA Energy Outlook (IEA 2010) and are within the range found in literature as reviewed by van Vuuren et al. (2012). The baseline projections generally do not include detailed assumptions on planned regional policies. Excluding these planned climate policies may lead to some overestimation of baseline emissions. The model's baseline and mitigation scenario forms the basis for the elaboration of assumptions on biofuels and electric vehicles in section "Biofuels" and "Electric vehicles", respectively. To assess the effectiveness of fuel efficiency standards, additional model runs were performed as elaborated below in section "Fuel efficiency standards".

\section{Fuel efficiency standards}

To project the effectiveness of fuel efficiency standards, the detailed TIMER travel and freight transport model as described by Girod et al. (2012) was used, which leads to energy demand and emission levels comparable to those in other transport emission models (Girod et al. 2013). As the effectiveness of fuel efficiency standards depends on the adoption of low-carbon alternatives without the standards, the effectiveness may depend on other policies in the transport sector. To test this, we performed two runs with the TIMER transport model: one in which the efficiency standards are introduced in a baseline case and one in which an efficiency standard is combined with a carbon tax of USD $200 / \mathrm{tCO}_{2}$ in the transport sector. 
The fuel efficiency standard in this study applies to passenger cars and light trucks on a global scale. The standard is based on the corporate average fuel economy (CAFE) standards with increasing stringency between 2016 and 2025, as proposed in the United States of America. More specifically, we applied a fuel efficiency standard increasing from 35 to 54.5 mile per gallon between 2016 and 2025 globally. In modeling terms, this means that cars that do not fulfill these requirements are no longer allowed on the market. More efficient fossil-fueled cars are made available as an alternative, but at a higher purchase price (of USD 950 per car in 2016 and USD 2900 per car by 2025), similar to the analysis by Deetman et al. (2014). Additionally, crucial assumptions are that (1) more efficient cars lead to lower driving costs per kilometer due to lower fuel and maintenance costs (Leamy 2013) and (2) fuel efficiency standard has no spillover effects. The first assumption leads to a slight increase in emissions because our model assumes a constant travel money budget, which means that the money saved by using less fuel is available for other forms of transport. As such, we account for the so-called rebound effect, which could partly or even fully counter the emission reductions (Small and Van Dender 2007; Vivanco et al. 2014). The latter assumption implies that there is no improvement in fuel efficiencies of cars that already fulfill the fuel efficiency requirements (see section "Discussion: a regional approach to clean transport technologies" for a discussion on this issue).

\section{Biofuels}

While biofuels are considered to be potentially carbonneutral, the potential for their sustainable production is projected to be limited (van Vuuren et al. 2009). Furthermore, it seems plausible that, over the coming decades, different sectors will be competing for the limited supply of biofuels. A wide range of biofuel types can be mixed with conventional transport fuels, which could partly mitigate the carbon dioxide emissions involved in traveling and freight transport (Bessou et al. 2011). At the same time, biofuel feedstocks are attractive for decarbonizing the electricity sector, especially while they enable negative emissions when combined with carbon capture and sequestration (BECCS). In fact, the application of BECCS has almost become a precondition to meeting the $2{ }^{\circ} \mathrm{C}$ target (van Vuuren et al. 2013). The importance of biofuels is also shown by the IEA BLUE map scenario, which aims at reducing energy-related $\mathrm{CO}_{2}$ emissions by $50 \%$ of 2005 levels by 2050. In this scenario, about 65 exajoules (EJ) of biomass feedstock is used for transport by 2050, compared with $80 \mathrm{EJ}$ for heat and power generation (IEA 2011). In the same scenario, only $37 \%$ of the biofuels used for transport is used for road passenger transport. The other transport modes road freight, shipping, and aviation use the major share of biofuels, because these modes have fewer alternatives for decarbonization.

Biofuel availability is not necessarily regionally bound, as transport over long distances is possible, mostly by ship. However, distribution costs make up a substantial share of biofuel costs (Hamelinck et al. 2005) and if large amounts of biofuels have to be imported it may threaten energy security. Given (1) the limited supply of biofuels, (2) the competition for biofuels across sectors, and (3) the relatively large distribution costs of biofuels, it is to be expected that the optimal use of biofuels in passenger transport differs between regions. For an indication of the regional differences in availability of biofuels for transport, we look at projections of total regional biofuel production and demand-both for the baseline and the 450 ppm mitigation scenario. These projections are based on a costoptimal allocation of production of and demand for biofuels, as assumed in the Environmental Outlook (OECD 2012).

\section{Electric vehicles}

Climate benefits of switching to alternative propulsion systems, such as battery electric vehicles, depend on the constitution of the power generation sector. This may change over time and may differ between alternative climate change policy strategies. In TIMER, a typical modern gasoline car has an energy efficiency of $1.13 \mathrm{MJ} / \mathrm{pkm}$ and has an emission factor of $92 \mathrm{~g} \mathrm{CO}_{2} / \mathrm{MJ}$. This compares to $0.34 \mathrm{MJ} / \mathrm{pkm}$ and an emission factor between 16 and $82 \mathrm{~g}$ $\mathrm{CO}_{2} / \mathrm{MJ}$ (depending on the region) for full electric cars. So even though driving electric cars is projected to emit less $\mathrm{CO}_{2}$ per $\mathrm{km}$, their carbon intensity could still differ by about a factor 5 across regions - as a result of differences in the carbon intensity of the power sector between regions. Such differences raise the question where policy support for electric cars would be most effective. To gain more insight into this, we compare the projected average $\mathrm{CO}_{2}$ intensity of electricity generation by 2050 between world regions, both in the baseline and under the mitigation policy scenario.

\section{Results}

Fuel efficiency standards

In the short term, fuel efficiency standards are expected to decrease emissions in all regions. In the longer term, however, fuel efficiency standards could be counterproductive in some countries-especially when combined with a carbon tax (Fig. 1). As shown earlier by Deetman 


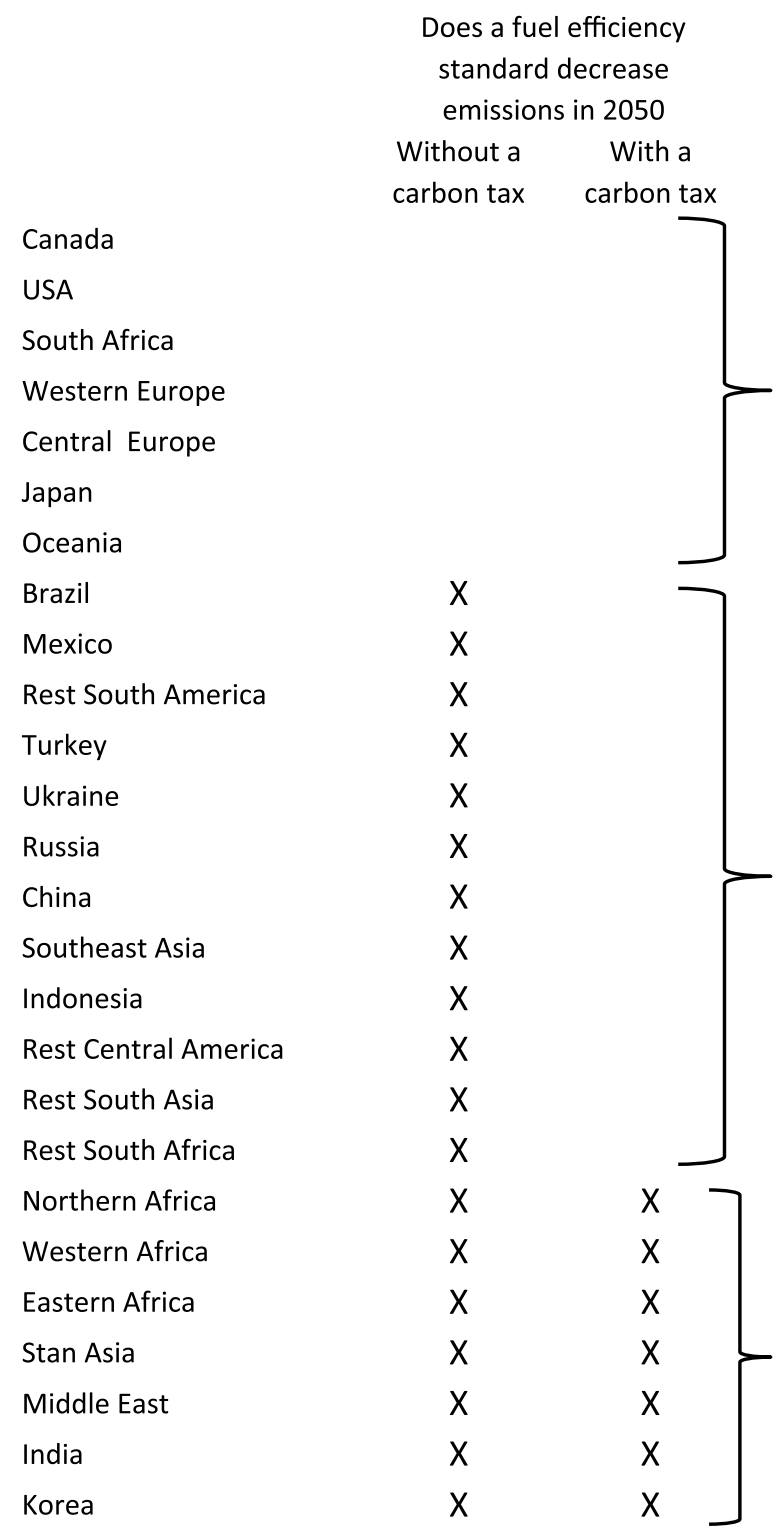
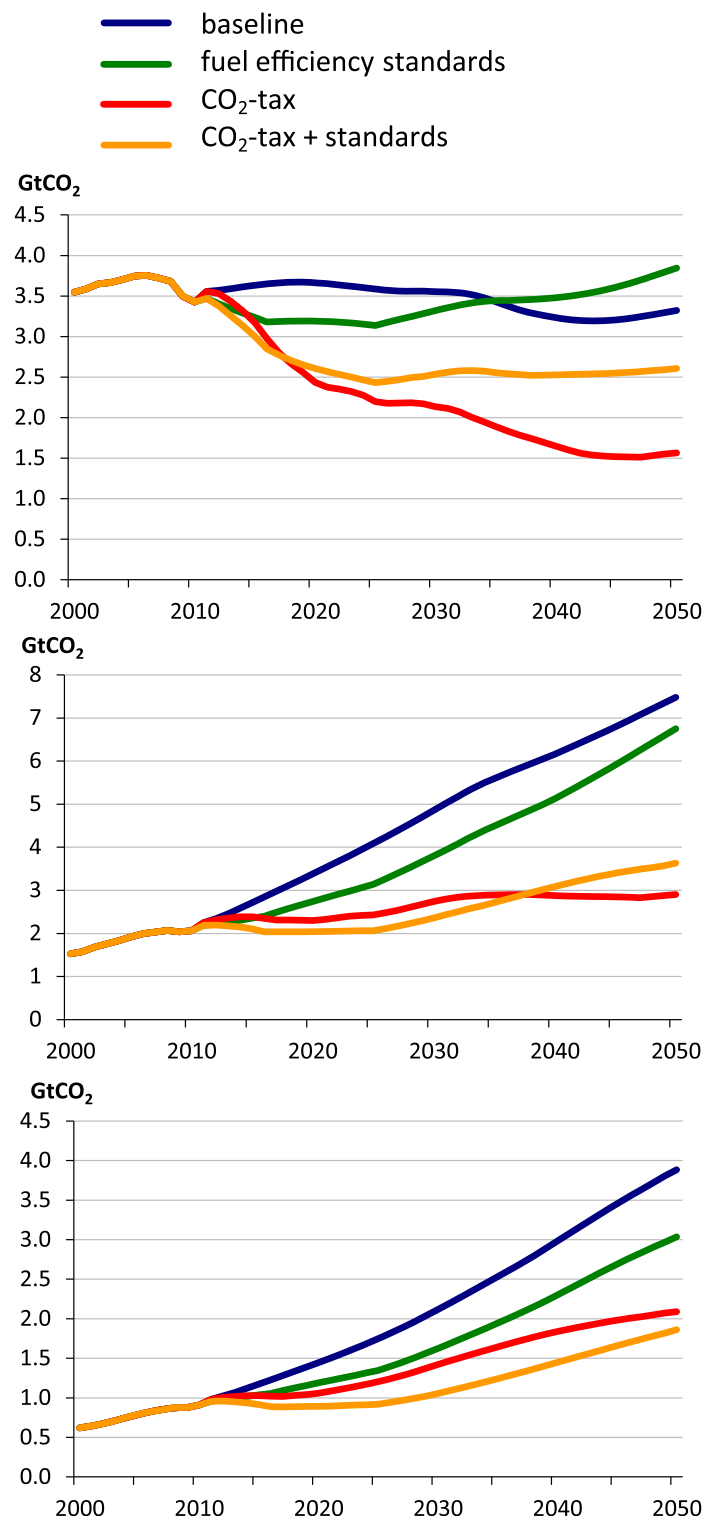

Fig. 1 Effectiveness of car fuel efficiency standards by region according to the TIMER transport model, with and without a carbon tax of USD $200 / \mathrm{tCO}_{2}$. The graphs at the right side show total

et al. (2014), the introduction of fuel efficiency standards in a region may lead to increased $\mathrm{CO}_{2}$ emissions in the long term if plugin hybrid electric cars are expected to gain a substantial market share. The reason is that efficiency standards lead to lower fuel costs of conventional fossilfueled cars, which outweighs the higher purchase price (see section "Fuel efficiency standards" and the discussion in Chapter 4). In such a case, efficiency standards lead to lower total average costs per kilometer, and therefore, conventional cars remain more competitive over plugin hybrid electric vehicles. In our baseline, hybrid electric cars are expected to have higher market shares in wealthier countries than in poorer countries, which implies that fuel passenger transport emissions for all regions shown at the left for four different scenarios. For a description of all countries in the presented regions, see Bouwman et al. (2006)

efficiency standards are generally less effective in wealthier countries. Introducing a carbon tax in our model leads to the widespread adoption of advanced low-emission vehicles in developing regions as well. If a fuel efficiency standard is enforced in addition to a carbon tax, unintended additional emissions occur by 2050 through the increased competitiveness of fossil-fueled cars in the majority of the regions.

For seven of the 26 world regions in our model, the fuel efficiency standard does not lead to lower emissions by 2050, both with and without a carbon tax. For another seven regions, the standard does lead to lower emissions by 2050 in both scenarios. For the remaining 12 regions, the 
Fig. 2 Regional biofuel demand and production in 2050, under baseline conditions (top graph) and a $450 \mathrm{ppm}$ mitigation scenario (bottom graph). Source OECD (2012)
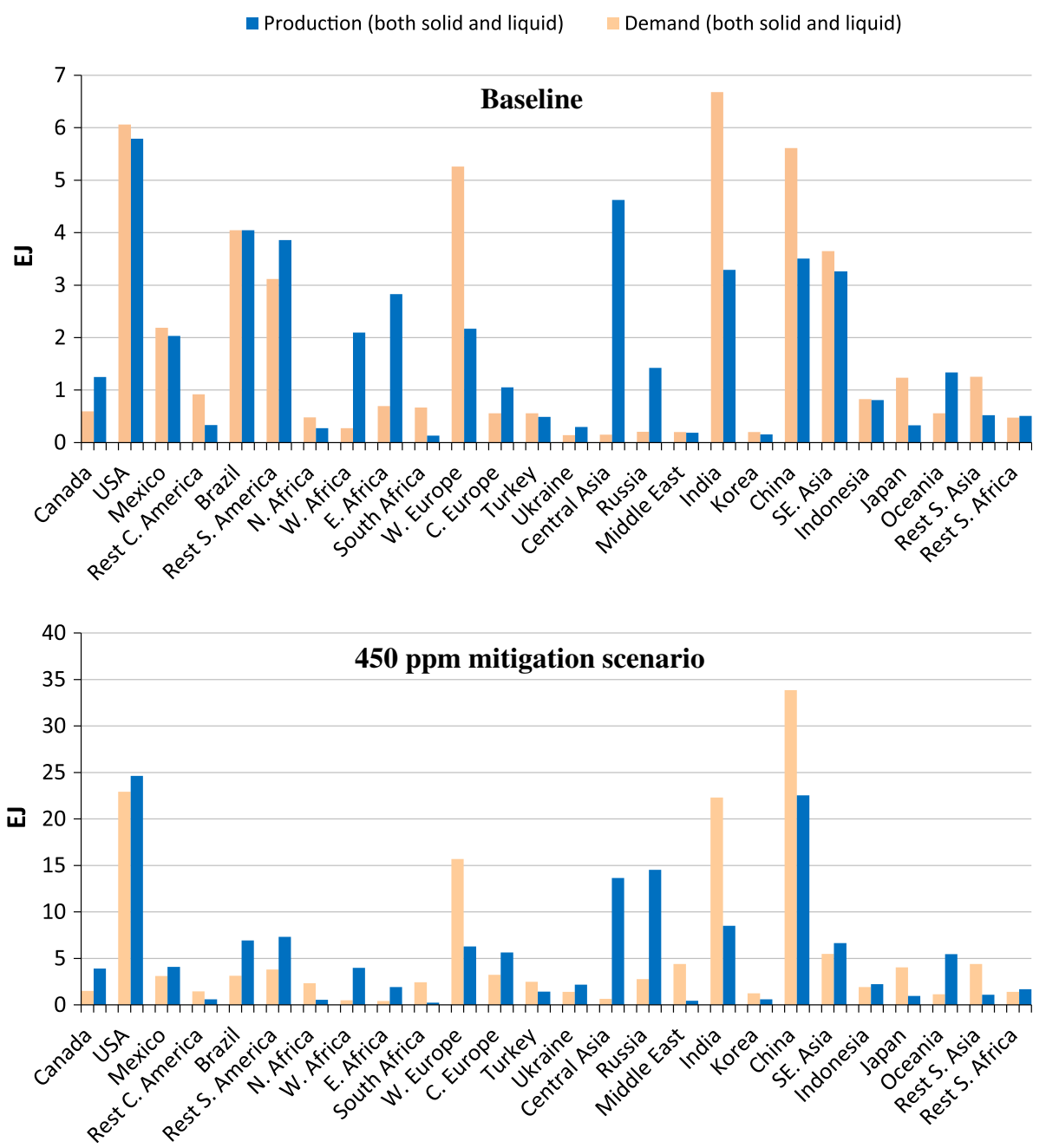

effectiveness of the efficiency standard depends on whether or not a carbon tax on transport is levied at the same time. This indicates the importance of an integral analysis of policy packages.

\section{Biofuels}

One of the factors relevant for the question whether or not to promote biofuels for transport is whether future-projected domestic demand for biofuels exceeds domestic supply. If this is the case, promoting biofuels may be less interesting from an energy security viewpoint, as it increases dependency on other regions. In the baseline, our model projects that globally about half of total biofuel production is used in the transport sector by 2050 . Regions for which total demand exceeds total supply of biofuels include Western Europe, India and the rest of south Asia, South Africa, China, and Japan (Fig. 2). These regions have a relatively low production potential for sustainable biofuels. If biofuels in transport were to be promoted in these regions, a high share of these fuels would likely be imported. Regions with the largest overproduction of biofuels include Central Asia, subSaharan Africa excluding South Africa, Russia, Central Europe, and Oceania.

In the $450 \mathrm{ppm}$ mitigation scenario, the production and demand for biofuels is obviously much higher. According to our model, in the mitigation scenario, a much lower share of production is used in the transport sector (about $10 \%$ ). For most of the regions for which supply exceeded demand for biofuels in the baseline scenario, supply exceeds demand in the $450 \mathrm{ppm}$ scenario as well. An exception is Brazil, which is projected to have a large overproduction of biofuels in a cost-optimal $450 \mathrm{ppm}$ scenario. In the Middle East, demand is much higher than supply in a cost-optimal $450 \mathrm{ppm}$ scenario. The regions with the largest import of biofuels in a cost-optimal $450 \mathrm{ppm}$ scenario again include Western Europe, India, China, and Japan.

The above information on itself is insufficient to guide any policy, but may be valuable when combined with insights into the other mitigation options considered in this 
Fig. 3 Projections for regional $\mathrm{CO}_{2}$ emission factors from electricity production by 2050 in the baseline and $450 \mathrm{ppm}$ mitigation scenario

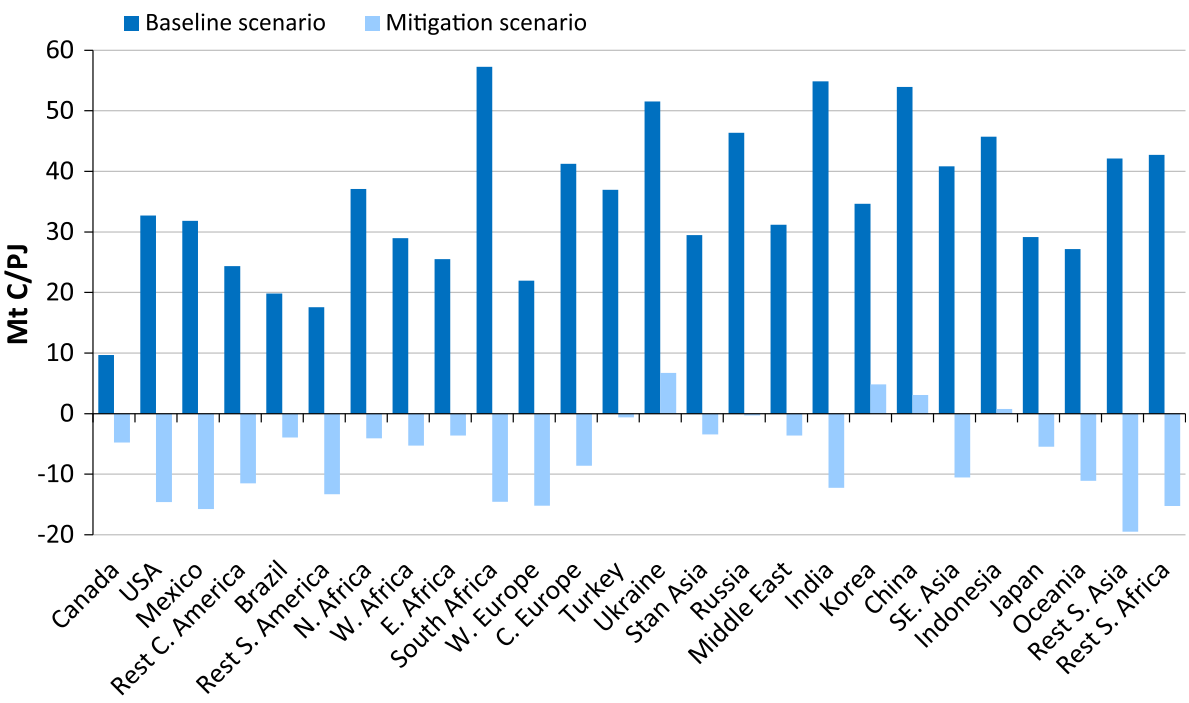

paper (see section "Discussion: a regional approach to clean transport technologies").

\section{Electric vehicles}

In the baseline scenario, high emission intensities of the power sector are projected for regions with a large share of coal in their power supply: South Africa, India, China, Russia, Ukraine, and Indonesia (Fig. 3). Regions with a high share of non-fossil energy (especially hydro-power) or natural gas in the baseline, such as Canada, South and Central America, and Western Europe, are projected to have relatively low emission intensities of the power supply sector. These figures indicate that without overall strong ambition in achieving deep $\mathrm{CO}_{2}$-emission reductions, from a climate perspective it is more interesting to deploy electric cars in Canada than in South Africa.

Obviously, the emission intensity of the power sector is much lower in the climate mitigation scenario. In most regions, $\mathrm{CO}_{2}$ emissions are even negative due to application of BECCS. There is no clear relation between the emission intensity in the baseline and in the mitigation scenario. For instance, South Africa has the highest emission intensity of power supply in the baseline, but one of the lowest in the mitigation scenario. A similar finding holds for India. This implies that the general level of climate policy ambition greatly influences the effectiveness of electric vehicles.

\section{Discussion: a regional approach to clean transport technologies}

Based on the above regional insights into biofuel availability, the effectiveness of fuel efficiency standards and the
$\mathrm{CO}_{2}$ intensity of the electricity sector, a provisional evaluation of mitigation policies for transport by world region can be formulated. Table 1 shows an example of such aqualitative evaluation. It should be interpreted as an example of possible use of insights from integrated assessment models to substantiate sensible regional policy approaches to mitigation in the transport sector. The scoring of policies is based on the outcomes of Figs. 1, 2 and 3, though the method is arguably arbitrary, as explained in the notes below the table. In short, a positive scoring for a certain policy in a certain region means that relative to other world regions (or, in the case of fuel efficiency standards, relative to the situation without the policy), the policy is effective according to our model projections.

The results in Table 1 show a differentiated picture across regions and the scenarios. According to our criteria, only three regions shows the same evaluation for all three policy options for the baseline and the mitigation scenario. For some regions, however, promoting electric vehicles seems like a relatively effective policy under both a baseline and mitigation scenario. These regions include OECD regions such as Western Europe, the USA and Oceania, but also regions such as Central America, India, and Southeast Asia. Differences in projected biofuel availability are less pronounced between the baseline and mitigation scenario. Regions with a relatively large projected overproduction, in both the baseline and mitigation scenario, include Canada, the USA, Mexico, South America, Western Africa, Central Europe, Russia, Central Asia, Southeast Asia, and Oceania.

It should be stressed that the policy options included in this study do not exclude each other. A combination of fuel efficiency standards and biofuels, for instance, could result in a larger mitigation potential than the implementation of one of these options separately. Finally, some regions- 
Table 1 Example of mitigation policy evaluation on passenger transport, discerning fuel efficiency standards, biofuels, and electric propulsion. A "+" indicates that the policy is effective, relative to other regions or relative to the situation without the policy. More specifically, fuel efficiency standards are considered to be effective when they lead to a reduction of emissions by 2050 (Fig. 1); biofuels are considered effective when the projected regional production is more than $10 \%$ higher than the projected demand for biofuels (Fig. 2); electric propulsion is considered an effective climate change mitigation technology when the power sector has a lower carbon intensity than the world average (Fig. 3)

\begin{tabular}{|c|c|c|c|c|c|c|}
\hline & \multicolumn{3}{|l|}{ Baseline } & \multicolumn{3}{|c|}{$450 \mathrm{ppm}$ mitigation scenario } \\
\hline & $\begin{array}{r}\text { Efficiency } \\
\text { standard }\end{array}$ & $\begin{array}{l}\text { Biofuel } \\
\text { availability }\end{array}$ & $\begin{array}{l}\text { Electric } \\
\text { vehicles }\end{array}$ & $\begin{array}{r}\text { Efficiency } \\
\text { standard }\end{array}$ & $\begin{array}{l}\text { Biofuel } \\
\text { availability }\end{array}$ & $\begin{array}{l}\text { electric } \\
\text { vehicles }\end{array}$ \\
\hline Canada & & + & + & & + & \\
\hline USA & & + & + & & + & + \\
\hline Mexico & + & + & + & & + & + \\
\hline Rest C. America & + & & + & & & + \\
\hline Brazil & + & + & + & & + & \\
\hline Rest S. America & + & + & + & & + & + \\
\hline N. Africa & + & & + & + & & \\
\hline W. Africa & + & + & + & + & + & \\
\hline E. Africa & + & + & + & + & + & \\
\hline South Africa & & & & & & + \\
\hline W. Europe & & & + & & & + \\
\hline Central Europe & & + & & & + & + \\
\hline Turkey & + & & + & & & \\
\hline Ukraine & + & + & & & + & \\
\hline Central Asia & + & + & + & + & + & \\
\hline Russia & + & + & & & + & \\
\hline Middle East & + & + & + & + & & \\
\hline India & + & & & + & & + \\
\hline Korea & + & & + & + & & \\
\hline China & + & & & & & \\
\hline SE. Asia & + & & & & + & + \\
\hline Indonesia & + & + & & & + & \\
\hline Japan & & & + & & & \\
\hline Oceania & & + & + & & + & + \\
\hline Rest S. Asia & + & & & & & + \\
\hline Rest S. Africa & + & + & & & + & + \\
\hline
\end{tabular}

especially in the mitigation scenario-do not score positively for any of the three policies. This does not mean that these policies do not lead to a reduction in emissions in these regions; it just indicates that in other regions, the policies may be more effective.

Obviously, both model assumptions and the definition of the criteria (applied as elaborated in the text below the table) are crucial to the outcomes and to the resulting evaluation. Therefore, further analysis should elaborate the relevance of outcomes from such a regional policy approach and could also explore the sensitivity of the outcomes to assumptions on, for instance, vehicle costs. Robustness of the analysis could also be enhanced when they are compared to outcomes of other models. A few other remarks and uncertainties to the applied analysis are discussed below.

First of all, it must be noted that the described effect of the fuel efficiency standards is a result of inputs and assumptions in the TIMER transport model and therefore not necessary the only potential outcome in a real world situation. Two issues are key in particular. First, the decrease in costs per kilometer for gasoline cars under the fuel efficiency standard is a result of assumptions on future fuel costs and the additional purchase price for more efficient cars. Secondly, we assume that there is no improvement in fuel efficiencies of cars that do fulfill the fuel efficiency requirements. Thereby, we ignore possible spillover effects of additional research and development, which could also lead to improved fuel efficiencies for (hybrid) electric cars. On the other hand, the development of market shares for (plugin) hybrid electric vehicles is itself dependent on uncertain assumptions on developments of costs. The TIMER travel assumptions lead to significant baseline market shares for plugin hybrids in wealthy countries only after 2030. Some studies hint that if current growth in adoption of hybrids would be continued, it would lead to significant market shares much earlier (Navigant Research 2013). This would also mean that the competition between fossil-fueled and hybrid electric vehicles would happen earlier than predicted by TIMER. 
Secondly, the conclusions on projected electricity emission factors (Fig. 3) are not based on the "additional" capacity needed to supply the increase in electricity demand from additional electric transportation, but on an average of the regions current generation capacity. In some regions, this is highly influenced by the existing hydropower capacity, which is expanding at very different rates regionally, and on top of that may be affected by climate change in very different ways (Hamududu and Killingtveit 2012). The current emission factor may thus be biased for characteristics of the existing stock and should preferably be determined over the additional capacity only. This rationale also holds for the case of negative emissions in the power sector under the mitigation scenario. An average negative emission factor for the electricity sector does not mean that additional electricity demand for passenger transport would be supplied by a net negative technology. For instance, when a region is at the maximum potential for BECCS deployment, the additional demand may be supplied by a fossil fuel plant.

Thirdly, a possible drawback of a regionally differentiated approach to mitigating $\mathrm{CO}_{2}$ from passenger transport is the lack in technological learning compared with a more homogenous choice of technologies.

Model outcomes such as presented here should always be interpreted against the assumptions that are made: They point at certain potential mechanisms, opportunities and risks in implementing policies. In that context, we feel that a more elaborate analysis of the possible dynamics in both the transport and the electricity sector is necessary before the indicative approach can be used to inform actual policies. One important improvement that could be required is a higher level of regional detail, as real policy decisions are made on a national level. Yet, we find the regional information from model experiments useful, because they substantiate long-term policy decisions in a sensible and a tangible way and clearly indicate how the effectiveness of policies could differ under different scenarios. Obviously, considerations for transportation policies may not be solely based on effectiveness in terms of greenhouse gas mitigation. Air quality concerns and energy independence, for instance, are well-known policy incentives, which could be incorporated in a regional analysis. The aim of this paper is to contribute to an open discussion to the practical application of model results to alleviate issues of choice in long-term policy planning.

Acknowledgments This work was supported by the RESPONSES European research project under the 7th Framework programme of the European Union, under Grant Agreement number 244092.

\section{References}

Barkenbus J (2009) Our electric automotive future: $\mathrm{CO}_{2}$ savings through a disruptive technology. Policy Soc 27:399-410. doi:10. 1016/j.polsoc.2009.01.005

Berndes G, Hansson J (2007) Bioenergy expansion in the EU: costeffective climate change mitigation, employment creation and reduced dependency on imported fuels. Energy Policy 35:5965-5979. doi:10.1016/j.enpol.2007.08.003

Bessou C, Ferchaud F, Gabrielle B, Mary B (2011) Biofuels, greenhouse gases and climate change. Rev Agron Sustain Dev 31:1-79. doi:10.1051/agro/2009039

Bouwman AF, Kram T, Klein Goldewijk K (2006) Integrated modelling of global environmental change. An overview of IMAGE 2.4. Netherlands Environmental Assessment Agency. Bilthoven: The Netherlands. Available at: www.pbl.nllimage

Calvin K, Clarke L, Krey V, Blanford G, Jiang K, Kainuma M, Kriegler E, Luderer G, Shukla PR (2012) The role of Asia in mitigating climate change: results from the Asia modeling exercise. Energy Econ 34:S251-S260. doi:10.1016/j.eneco.2012. 09.003

Chapman L (2007) Transport and climate change: a review. J Transp Geogr 15:354-367. doi:10.1016/j.jtrangeo.2006.11.008

Clarke L, Edmonds J, Krey V, Richels R, Rose S, Tavoni M (2009) International climate policy architectures: overview of the EMF 22 International Scenarios. Energy Econ 31:S64-S81. doi:10. 1016/j.eneco.2009.10.013

Deetman S, Hof AF, Pfluger B, van Vuuren DP, Girod B, van Ruijven BJ (2013) Deep greenhouse gas emission reductions in Europe: exploring different options. Energy Policy 55:152-164. doi:10. 1016/j.enpol.2012.11.047

Deetman S, Hof AF, van Vuuren DP (2014) Deep greenhouse gas emission reductions: a global bottom-up model approach Clim Policy (in press). doi:10.1080/14693062.2014.912980

Edenhofer O, Knopf B, Barker T, Baumstark L, Bellevrat E, Chateau $B$, Criqui $P$, Isaac $M$, Kitous $A$, Kypreos $S$, Leimbach $M$, Lessmann K, Magné B, Scrieciu Š, Turton H, Van Vuuren DP (2010) The economics of low stabilization: model comparison of mitigation strategies and costs. Energ J 31:11-48. doi:10.5547/ ISSN0195-6574-EJ-Vol31-NoSI-2

EPA, NHTSA (2012) 2017 and later model year light-duty vehicle greenhouse gas emissions and corporate average fuel economy standards. https://www.federalregister.gov/articles/2012/10/15/ 2012-21972/2017-and-later-model-year-light-duty-vehicle-green house-gas-emissions-and-corporate-average-fuel

European Parliament, European Council (2009) Directive 2009/28/ EC of the European parliament and of the council of 23 April 2009 on the promotion of the use of energy from renewable sources and amending and subsequently repealing Directives 2001/77/EC and 2003/30/EC. European Parliament and the Council of the European Union. http://europa.eu/legislation summaries/energy/renewable_energy/en0009_en.htm

Girod B, van Vuuren DP, Deetman S (2012) Global travel within the $2{ }^{\circ} \mathrm{C}$ climate target. Energy Policy 45:152-166. doi:10.1016/j. enpol.2012.02.008

Girod B, van Vuuren DP, Grahn M, Kitous A, Kim SH, Kyle P (2013) Climate impact of transportation A model comparison. Clim Change 118:595-608. doi:10.1007/s10584-012-0663-6

Hamelinck CN, Suurs RAA, Faaij APC (2005) International bioenergy transport costs and energy balance. Biomass Bioenergy 29:114-134. doi:10.1016/j.biombioe.2005.04.002

Hamududu B, Killingtveit A (2012) Assessing climate change impacts on global hydropower. Energies 5:305-322. doi:10. 3390/en5020305 
Hawkins TR, Singh B, Majeau-Bettez G, Strømman AH (2013) Comparative environmental life cycle assessment of conventional and electric vehicles. J Ind Ecol 17:53-64. doi:10.1111/j. 1530-9290.2012.00532.x

IEA (2010) World energy outlook 2010. International Energy Agency, Paris. http://www.worldenergyoutlook.org/

IEA (2011) Technology roodmap: biofules for transport. OECD/IEA, Paris. http://www.iea.org/publications/freepublications/publication/ name,3976,en.html

Kim HJ, Keoleian GA, Skerlos SJ (2011) Economic assessment of greenhouse gas emissions reduction by vehicle lightweighting using aluminum and high-strength steel. J Ind Ecol 15:64-80. doi:10.1111/j.1530-9290.2010.00288.x

Kley F, Wietschel M, Dallinger D (2012) Evaluation of European electric vehicle support schemes. Working paper sustainability and innovation, No. S7/2010. http://hdl.handle.net/10419/40019

Kushnir D, Sandén BA (2012) The time dimension and lithium resource constraints for electric vehicles. Resour Policy 37:93-103. doi:10.1016/j.resourpol.2011.11.003

Leamy E (2013) New fuel economy standards: cars will cost more to buy, less to drive. ABC news, June 18th 2013. http://abcnews.go. com/Business/fuel-economy-standards-cars-cost-buy-drive/story? id=19421504. Accessed 3 Feb 2014

Mazzi EA, Dowlatabadi H (2007) Air quality impacts of climate mitigation: UK policy and passenger vehicle choice. Environ Sci Technol 41:387-392. doi:10.1021/es060517w

Molony T, Smith J (2010) Briefing: biofuels, food security, and Africa. Afr Aff 109:489-498. doi:10.1093/afraf/adq019

Navigant Research (2013) Electric vehicle market forecasts. Global forecasts for light duty hybrid, plug-in hybrid, and battery electric vehicle sales and vehicle parc: 2013-2022. http://www. navigantresearch.com/research/electric-vehicle-market-forecasts

OECD (2012) OECD environmental outlook to 2050: the consequences of inaction. OECD, Paris. http://www.oecd.org/environ ment/indicators-modelling-outlooks/oecdenvironmentaloutlookto 2050theconsequencesofinaction.htm
Richardson DB (2013) Electric vehicles and the electric grid: a review of modeling approaches impacts, and renewable energy integration. Renew Sustain Energy Rev 19:247-254. doi:10.1016/j.rser. 2012.11.042

Small KA, Van Dender K (2007) Fuel efficiency and motor vehicle travel: the declining rebound effect. Energy J 28:25-51

Van Mierlo J, Maggetto G, Lataire P (2006) Which energy source for road transport in the future? A comparison of battery, hybrid and fuel cell vehicles. Energy Convers Manag 47:2748-2760. doi:10. 1016/j.enconman.2006.02.004

van Vuuren DP (2006) Energy systems and climate policy-Longterm scenarios for an uncertain future. Dissertation, Utrecht University. http://dspace.library.uu.nl/handle/1874/21449

van Vuuren DP, den Elzen MGJ, Lucas PL, Eickhout B, Strengers BJ, van Ruijven B, Wonink S, van Houdt R (2007) Stabilizing greenhouse gas concentrations at low levels: an assessment of reduction strategies and costs. Clim Change 81:119-159. doi:10. 1007/s10584-006-9172-9

van Vuuren DP, van Vliet J, Stehfest E (2009) Future bio-energy potential under various natural constraints. Energy Policy 37:4220-4230. doi:10.1016/j.enpol.2009.05.029

van Vuuren DP, Riahi K, Moss R, Edmonds J, Thomson A, Nakicenovic N, Kram T, Berkhout F, Swart R, Janetos A, Rose SK, Arnell N (2012) A proposal for a new scenario framework to support research and assessment in different climate research communities. Glob Environ Change 22:21-35. doi:10.1016/j. gloenvcha.2011.08.002

van Vuuren DP, Deetman S, van Vliet J, van den Berg M, van Ruijven BJ, Koelbl B (2013) The role of negative CO2 emissions for reaching $2{ }^{\circ} \mathrm{C}$-insights from integrated assessment modelling. Clim Change 118:15-27. doi:10.1007/s10584-012-0680-5

Vivanco DF, Kemp R, van der Voet E, Heijungs R (2014) Using LCA-based decomposition analysis to study the multidimensional contribution of technological innovation to environmental pressures. J Ind Ecol (in press). doi:10.1111/jiec.12118 